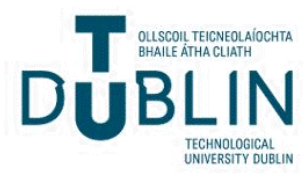

Technological University Dublin

ARROW@TU Dublin

\section{Elemental analysis of fish feed by laser-induced breakdown spectroscopy}

\author{
Md. Ashraful Alam \\ Technological University Dublin, Alam.Ashraful@TUDublin.ie \\ Camille Pasquet \\ Technological University Dublin, Camille.Pasquet@tudublin.ie \\ Fintan Moran \\ Technological University Dublin, fintan.moran@tudublin.ie
}

See next page for additional authors

Follow this and additional works at: https://arrow.tudublin.ie/schfsehart

Part of the Food Science Commons

\section{Recommended Citation}

Alam, Md. Ashraful; Pasquet, Camille; Moran, Fintan; Cullen, Patrick; Sullivan, Carl; Casado-Gavalda, Maria; and Markiewicz-Keszycka, Maria, "Elemental analysis of fish feed by laser-induced breakdown spectroscopy" (2020). Articles. 407.

https://arrow.tudublin.ie/schfsehart/407

This Article is brought to you for free and open access by the School of Food Science and Environmental Health at ARROW@TU Dublin. It has been accepted for inclusion in Articles by an authorized administrator of ARROW@TU Dublin. For more information, please contact arrow.admin@tudublin.ie, aisling.coyne@tudublin.ie, gerard.connolly@tudublin.ie.

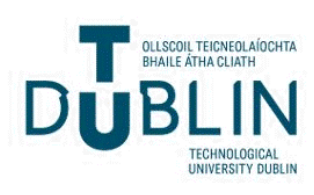




\section{Authors}

Md. Ashraful Alam, Camille Pasquet, Fintan Moran, Patrick Cullen, Carl Sullivan, Maria Casado-Gavalda, and Maria Markiewicz-Keszycka 


\title{
Elemental analysis of fish feed by laser-induced breakdown spectroscopy
}

\author{
Md. Ashraful Alam ${ }^{\mathrm{a}, *}$, Maria Markiewicz-Keszycka ${ }^{\mathrm{a}}$, Camille Pasquet ${ }^{\mathrm{a}}$, Fintan Moran ${ }^{\mathrm{a}}$, \\ Patrick J. Cullen ${ }^{\mathrm{a}, \mathrm{b}}$, Carl Sullivan ${ }^{\mathrm{a}}$, Maria P. Casado-Gavalda ${ }^{\mathrm{a}}$ \\ ${ }^{a}$ School of Food Science and Environmental Health, Technological University Dublin, Cathal Brugha St, Dublin 1, Ireland \\ ${ }^{\mathrm{b}}$ School of Chemical and Biomolecular Engineering, University of Sydney, Australia
}

A R T I C L E I N F O

\section{Keywords:}

Aquafeed

Chromium

LIBS

ICP-MS

Chemometric

\begin{abstract}
A B S T R A C T
In this study, the potential of laser-induced breakdown spectroscopy (LIBS) as an efficient multi-elemental quantification tool for fish feed is determined. A particular focus of this paper is total chromium, an essential element that has the potential to be toxic and carcinogenic. In total six elements, four macro-elements ( $\mathrm{Ca}, \mathrm{Fe}, \mathrm{K}$ and $\mathrm{Mg}$ ) and two micro-elements ( $\mathrm{Cr}$ and $\mathrm{Rb}$ ), were modelled using LIBS spectra of aquafeed samples. Reference analysis was conducted via inductively coupled plasma mass spectrometry (ICP-MS) and showed good agreement with LIBS predictions. These results provide evidence that LIBS has the potential to be utilized in the field as a real-time screening tool for establishing the elemental composition of a range of fish feeds.
\end{abstract}

\section{Introduction}

Fish and fish products are considered a valuable part of the human diet; containing a good balance of minerals, proteins and vitamins. Historically, fish were consumed as wild catch. However, increases in the human population and a decline in wild fish stocks, associated with over-harvesting and water pollution, have led to a global trend in aquaculture as a solution to satisfy demand. This growth is supported through developments in fish feed production, a key component of any aquaculture system, both from a manufacturing and regulatory point of view. Elemental analysis of both salutary and deleterious elements such as trace elements in feed should be an essential part of any quality management system for fish farms. For example, in countries such as Bangladesh, with substantial tanning industries, chromium entering the food chain via feed is of particular concern [1-3].

A literature review highlights the popularity of spectroscopic techniques and mass spectrometry as a means of determining the elemental composition of fish feed. Simultaneous electrothermal atomic absorption spectrometry (SIMAAS) was used to determine $\mathrm{As}, \mathrm{Cd}, \mathrm{Cu}$ and $\mathrm{Pb}$ levels in fish feed [4]. Fish feed samples from the south-western region of Bangladesh have been assessed for trace element (As, Cd, Cr, $\mathrm{Hg}$ and $\mathrm{Pb}$ ) contamination by AAS (atomic absorption spectrometry) [5]. Souza et al. [6] evaluated the following elements $\mathrm{Al}, \mathrm{B}, \mathrm{Ca}, \mathrm{Fe}, \mathrm{K}, \mathrm{Mg}, \mathrm{Mn}, \mathrm{Na}$, $\mathrm{S}, \mathrm{P}$ and $\mathrm{Zn}$ by ICP-OES (inductively coupled plasma-optical emission spectrometry); as well as $\mathrm{As}, \mathrm{Ba}, \mathrm{Cd}, \mathrm{Cr}, \mathrm{Cu}, \mathrm{Ni}, \mathrm{Pb}, \mathrm{Sb}, \mathrm{Se}, \mathrm{Sr}$ and $\mathrm{V}$ in fish feed by ICP-MS (inductively coupled plasma-mass spectrometry). Also, instrumental neutron activation analysis (INAA) has been used to estimate $\mathrm{Ca}, \mathrm{Cu}, \mathrm{Fe}, \mathrm{Mg}, \mathrm{Mn}, \mathrm{Na}, \mathrm{P}$, and $\mathrm{Zn}$ in fish feed [7]. These established techniques are very sensitive and accurate; however in the case of AAS and ICP methods extensive sample preparation such as dissolution and digestion is required. Pressurized gas is also a feature of AAS and ICP approaches while INAA requires a reactor core thus limiting their potential as an at-line production or in-field tool.

In the last decade, there has been a growing interest in the elemental analysis of food products by laser-induced breakdown spectroscopy (LIBS). This technique typically requires little to no sample preparation, is rapid and can be operated without the need for gases. Such features make it a potential technique for in-field testing or as a Process Analytical Technology. Its potential at mapping elemental spatial distributions has also been demonstrated $[8,9]$.

LIBS has been demonstrated for mineral analysis of a wide variety of organic matrices. Gondal et al. [10] analysed $\mathrm{Br}, \mathrm{Ca}, \mathrm{Cu}, \mathrm{Fe}, \mathrm{K}$ and $\mathrm{Si}$ in tea. While Baskali-Bouregaa et al. [11] identified tea geographical origin using LIBS elemental fingerprinting associate with ICP-MS measurement. In another study, Dixit et al. [12] determined Rb levels in beef samples. LIBS has accurately predicted ash levels as well as quantified $\mathrm{Mg}$ and $\mathrm{K}$ contents in gluten free powders [13]. Trace elements such as $\mathrm{Cd}$ and $\mathrm{Pb}$ have been determined in rice [14] as well as $\mathrm{Cr}$ in rice leaves [15].

This study examines the potential of LIBS as a rapid elemental analysis approach for fish feed. A $150 \mathrm{~mJ}$ LIBS system, in combination with chemometric techniques, was used to model six elements (i.e. four macro-elements: $\mathrm{Ca}, \mathrm{Fe}, \mathrm{K}$ and $\mathrm{Mg}$ and two micro-elements: $\mathrm{Cr}$ and $\mathrm{Rb}$ ) in a variety of fish feed samples sourced from Bangladesh. Also, the

\footnotetext{
* Corresponding author.

E-mail address: Alam.Ashraful@tudublin.ie (Md. A. Alam).
} 
ability of LIBS as a method for visualizing sample homogeneity/heterogeneity is displayed via chemical maps.

\section{Materials and methods}

\subsection{Sample material and preparation}

Commercial fish feed powder samples were obtained from several aquafeeds manufacturers in Bangladesh. A total of eight different types of dry feed in powder form, suitable for freshwater fish, were used in this study. The product manufacturers state that the feed is suitable for the following fish and their developmental stages: carp starter, carp grower, pangus grower, pangus finisher, telapia nursery, telapia starter, general fish feed powder I and general fish feed powder II.

In order to test the quantitative and qualitative capabilities of LIBS, samples were divided into a calibration set for quantitative analysis and a qualitative set for fingerprint discrimination. The quality of the pellet's mechanical strength can be improved by the addition of a binder. Binders are mainly composed of hydrogen and carbon ensuring minimum interference with the main elements in a spectrum [16]. Five mixtures with different proportion of binder (3644-Ultrabind, Spex, UK) and aquafeed (general fish feed powder II) containing $0 \%, 20 \%$, $40 \%, 60 \%$ and $80 \%$ of fish feed content $\left(\mathrm{w} \mathrm{w}^{-1}\right)$ were prepared as quantitative set.

The seven remaining aquafeeds correspond to the qualitative set. For these seven types of feed a 40:60 ratio $\left(\mathrm{w} \mathrm{w}^{-1}\right)$ mixture of binder to aquafeed were prepared. All sample mixtures were precisely weighed ( $500 \pm 10 \mathrm{mg}$ ) having been prepared in triplicates by adding $200 \mathrm{mg}$ of binder and $300 \mathrm{mg}$ of fish feed into a plastic tube which was then manually shaken and subsequently vortexed. Mixtures are then transferred into a $13 \mathrm{~mm}$ diameter stainless steel die and pelleted using a hydraulic press (GS01160, Specac Ltd., Orpington, UK) by applying a pressure of 10 tonnes for $3 \mathrm{~min}$.

In addition, to illustrate LIBS's ability to detect spatial features two heterogeneous pellets were prepared following the previous procedure. The two pellets of approximately $500 \mathrm{mg}$, were heterogeneously prepared with one side of the pellet composed of $100 \%$ binder and the other side a 80:20 ratio $\left(\mathrm{w} \mathrm{w}^{-1}\right)$ of binder to aquafeed. The second pellet consisted of a 100\% binder on one side and a 40:60 ratio $\left(\mathrm{w} \mathrm{w}^{-1}\right)$ of binder to aquafeed on the other side.

In summary, 15 pellets ( 5 mixtures in triplicates) were employed for quantification, 21 pellets ( 7 aquafeeds in triplicates) for qualitative analysis and 2 pellets for chemical mapping.

\subsection{Reference method}

\subsubsection{Microwave assisted digestion and sample preparation}

For the analysis, $500 \mathrm{mg}$ of sample was transferred to a microwave digestion tube. Thereafter, $10 \mathrm{ml}$ of nitric acid (69\%, Sigma Aldrich) was added and left to stand for $15 \mathrm{~min}$. The digestion tubes were screw caped and set in a microwave digester to complete digestion (CEM Corp. MARS 6, Matthews, NC, USA). The microwave digestion settings were temperature: $210{ }^{\circ} \mathrm{C}$, pressure: $800 \mathrm{psi}$, power: $1000-1800 \mathrm{w}$, ramp time: $20-25 \mathrm{~min}$ and hold time: $15 \mathrm{~min}$. After complete digestion and cooling, the resultant solutions were transferred to plastic, metalfree, $100 \mathrm{ml}$ volumetric flask and ultra-pure deionized water was added until the volume mark was reached. Blank samples and certified reference material (CRM) - Non-Fat Milk Powder (ERM-BD151) - were processed with unknown samples. Aqueous calibration standard solutions were prepared by dilution of the multi-element calibration standard-2A (Agilent Technologies, Japan). For $\mathrm{Ca}, \mathrm{Mg}, \mathrm{K}$ and $\mathrm{Fe}$ analysis, the samples required further dilution by a factor of one hundred in order to fit within the calibration range of the reference method. The entire procedure was replicated for each fish feed sample.

\subsubsection{ICP-MS instrumentation}

Inductively coupled plasma mass spectrometry (ICP-MS) with an octopole reaction system (ORS) was used for the elemental analysis of all fish feed samples (7900 ICP-MS, Agilent, Japan). The plasma was generated via argon gas (purity of 99.9999\%) using a plasma flow rate of $15 \mathrm{~L} \mathrm{~min}^{-1}$, the auxiliary and nebuliser gas both had a flow rate of $1 \mathrm{~L} \mathrm{~min}^{-1}$. The induction coil was operated at a radio-frequency of $27 \mathrm{MHz}$ with a power of $1.5 \mathrm{~kW}$. The ORS was operated using $\mathrm{He}$ (collision mode) with a gas flow rate of $5 \mathrm{ml} \mathrm{min}^{-1}$.

In this work, all reagents used were of analytical grade. Ultra-pure deionized water (resistivity of $18.2 \mathrm{~m} \Omega \mathrm{cm}^{-1}$ ) was generated in-house (Adrona B30/Integrity +, Riga, Lativa). Prior to use, all vessels used were decontaminated in a nitric acid solution $\left(10 \% \mathrm{v} \mathrm{v}^{-1}\right)$ for $24 \mathrm{~h}$ $[17,18]$ after which they were washed with ultra-pure deionized water three times and dried in an electric oven at $45{ }^{\circ} \mathrm{C}$.

\subsection{LIBS instrumentation and measurement}

\subsubsection{Instrument set-up}

LIBS experiments were performed using a LIBS-6 system (Applied Photonics Ltd., Skipton, UK) which is constituted of a $150 \mathrm{~mJ}$ Q-switched Nd:YAG laser (Nano SG 150-10, Litron lasers Ltd., Rugby, UK) operating at $1064 \mathrm{~nm}$ wavelength with a pulse duration of $5 \mathrm{~ns}$ and a repetition rate of $1 \mathrm{~Hz}$ coupled with six spectrometers (AvaSpec, Avantes BV, Apeldoorn, Netherlands) covering the spectral range of 181-904 nm. Plasma emission was recorded at a $1.27 \mu$ s delay time with an integration time of $1.1 \mathrm{~ms}$.

\subsubsection{Measurement}

For each pellet, spectra were recorded 3 consecutive times at 100 different spatial locations, following a $10 \times 10$ grid pattern with an approximately $0.7 \mathrm{~mm}$ inter-measurement distance using a motorised X-Y-Z sample chamber (XYZ-750, Applied Photonics Limited, Skipton North Yorkshire, United Kingdom) at the optimum focal length of approximately $80 \mathrm{~mm}$. Measurements were conducted operating the laser in a continuous mode.

\subsection{Chemometric analysis}

Multivariate analysis was performed using R [19] and the "pls" package [20] for PLSR (partial least square regression) modelling, PCA (Principal Component Analysis) for qualitative analysis along with other in-house functions for quantitative analysis.

In order to correct non-linearities and signals variation introduced by fluctuations in the laser pulse energy and matrix effects, the spectral data was initially pre-processed. Firstly, data collected for each pellet were baseline corrected followed by spectral normalization against the $\mathrm{H}$ I atomic spectral line $(656.24 \mathrm{~nm})$. This transformation is a standard score calculation for each point of the signal in order to normalise any variation between point measurements within replicates.

For qualitative analysis, PCA was applied to data chosen for fingerprint discrimination in order to reduce the dimensionality of the dataset while retaining as much of the variation present as possible [21].

For quantitative analysis, the median of the 100 locations of the calibration set was used to obtain a single spectrum per analysed pellet. In this study, the use of the median has been preferred to the average, as the median is less affected by outliers. The spectral range where the main spectral line emissions relating to $\mathrm{Ca}, \mathrm{Cr}, \mathrm{Fe}, \mathrm{Mg}, \mathrm{K}$ and $\mathrm{Rb}$ occur was chosen to build six different PLSR models. PLSR is a multivariate technique which develops a linear regression model by projecting the predicted (spectral data) and observed variables (elemental chemical analysis) to a new space to which $\mathrm{X}$-predicted and $\mathrm{Y}$-observed data are transferred [22]. Processed data acquired for the calibration set containing $0 \%, 40 \%$ and $80 \%$ fish feed $(n=9)$ were used to develop the calibration model, along with their elemental chemical analysis values 
Table 1

Reference analysis (ICP-MS) contents for both macro-elements (Ca, Fe, K and Mg) and micro-elements ( $\mathrm{Cr}$ and $\mathrm{Rb}$ ) of eight aquafeeds.

\begin{tabular}{|c|c|c|c|c|c|c|}
\hline Sample & $\mathrm{Ca}\left(\mathrm{mg} \mathrm{g}^{-1}\right)^{\mathrm{a}}$ & $\mathrm{Fe}\left(\mathrm{mg} \mathrm{g}^{-1}\right)^{\mathrm{a}}$ & $\mathrm{K}\left(\mathrm{mg} \mathrm{g}^{-1}\right)^{\mathrm{a}}$ & $\operatorname{Mg}\left(\mathrm{mg} \mathrm{g}^{-1}\right)^{\mathrm{a}}$ & $\operatorname{Cr}\left(\mu g g^{-1}\right)^{a}$ & $\mathrm{Rb}\left(\mu \mathrm{g} \mathrm{g}^{-1}\right)^{\mathrm{a}}$ \\
\hline Carp starter & $3.13 \pm 0.16$ & $0.33 \pm 0.11$ & $10.2 \pm 0.3$ & $4.88 \pm 0.16$ & $7.77 \pm 0.22$ & $30.2 \pm 0.8$ \\
\hline Carp grower & $2.20 \pm 0.06$ & $0.59 \pm 0.15$ & $8.16 \pm 0.15$ & $5.62 \pm 0.11$ & $8.57 \pm 0.63$ & $29.3 \pm 0.3$ \\
\hline Pangus grower & $2.25 \pm 0.06$ & $0.19 \pm 0.09$ & $8.14 \pm 0.24$ & $6.03 \pm 0.15$ & $7.29 \pm 0.30$ & $33.3 \pm 1.2$ \\
\hline Pangus finisher & $1.06 \pm 0.03$ & $0.49 \pm 0.00$ & $8.41 \pm 0.13$ & $5.00 \pm 0.08$ & $2.88 \pm 0.06$ & $39.6 \pm 0.4$ \\
\hline Telapia nursery & $2.98 \pm 0.37$ & $0.49 \pm 0.06$ & $10.5 \pm 1.0$ & $2.17 \pm 0.28$ & $1.27 \pm 0.30$ & $15.1 \pm 1.4$ \\
\hline Telapia starter & $16.3 \pm 0.4$ & $0.36 \pm 0.00$ & $137 \pm 2$ & $9.97 \pm 0.10$ & $3.72 \pm 0.30$ & $25.5 \pm 0.9$ \\
\hline General fish feed powder I & $1.93 \pm 0.13$ & $0.66 \pm 0.19$ & $10.7 \pm 0.5$ & $5.95 \pm 0.29$ & $1.48 \pm 0.11$ & $17.5 \pm 0.7$ \\
\hline General fish feed powder II & $4.61 \pm 0.23$ & $0.54 \pm 0.18$ & $11.2 \pm 0.4$ & $3.37 \pm 0.13$ & $103 \pm 5$ & $36.4 \pm 1.4$ \\
\hline
\end{tabular}

${ }^{\mathrm{a}}$ mean \pm standard deviation $(\mathrm{n}=3)$.

extracted from ICP-MS analysis. The remaining data of the calibration set containing $20 \%$ and $60 \%$ fish feed $(n=6)$, along with their elemental chemical analysis values, were used as the validation sample set. The method of leave-one-out was used for cross validation in order to avoid either over- or under-fitting of the models. The calibration model was evaluated by determining the optimum number of components based on the root mean square error in cross validation (RMSECV) and coefficient of determination in cross validation $\left(\mathrm{R}_{\mathrm{cv}}^{2}\right)$. The prediction accuracy of the developed calibration model was evaluated by calculating the root mean square error of prediction (RMSEP) and the corresponding coefficients of determination in prediction $\left(\mathrm{R}_{\mathrm{p}}^{2}\right)$.

\section{Results and discussion}

\subsection{Reference ICP-MS analysis}

These elemental results are expressed as $\mathrm{mg}^{-1}$ for $\mathrm{Ca}, \mathrm{Fe}, \mathrm{K}$ and $\mathrm{Mg}$ and as $\mu \mathrm{g} \mathrm{g}^{-1}$ for $\mathrm{Cr}$ and $\mathrm{Rb}$ (Table 1). Note, as the binder did not contain any detectable levels of these elements, it is omitted from Table 1. The elemental concentrations found in the eight fish feed samples were in the following descending order: $\mathrm{K}>\mathrm{Ca}>\mathrm{Mg}>$ $\mathrm{Fe}>\mathrm{Cr}>\mathrm{Rb}$. As expected, the four macro-elements (Ca, Fe, $\mathrm{K}$ and $\mathrm{Mg}$ ) are present in higher concentrations than the two micro-elements ( $\mathrm{Cr}$ and $\mathrm{Rb}$ ). The aquafeeds contained levels of chromium between 1 and $9 \mu \mathrm{g} \mathrm{g}^{-1}$, except for one sample, general fish feed II, which contained more than $100 \mu \mathrm{g} \mathrm{g}^{-1}$. Due to its higher $\mathrm{Cr}$ content as measured with the reference ICP-MS analysis, the general fish feed powder II was selected as the calibration aquafeed sample for mineral quantification purposes with LIBS.

\subsection{Qualitative set}

\subsubsection{Spectral analysis and PCA}

LIBS spectra of four different aquafeeds samples (carp starter, pangus finisher, telapia nursery and general fish feed powder I), selected randomly, are presented to illustrate the qualitative potential of LIBS. Fig. 1 A. shows the baseline corrected and normalised spectra, representing the median value of 100 locations for one replicate, picked randomly. The spectral lines were associated with the most probable elements emitting at the observed wavelengths, using the spectral lines provided by the NIST database as a reference [23].

In Fig. $1 \mathrm{~A}$., for all samples, the strongest intensities were observed at $589.05 \mathrm{~nm}$ and $589.59 \mathrm{~nm}$ (both atomic lines) which are generally associated with sodium. Followed by the doublet peak $(766.46 \mathrm{~nm}$ and $769.93 \mathrm{~nm}$, both atomic lines) of potassium, the multiple peaks at $393.39 \mathrm{~nm}$ (ionic line), $396.86 \mathrm{~nm}$ (ionic line), $422.65 \mathrm{~nm}$ (atomic line) and $616.28 \mathrm{~nm}$ (atomic line) attributed to calcium, the peaks at $279.56 \mathrm{~nm}$ (ionic line) and $518.40 \mathrm{~nm}$ (atomic line) of magnesium and finally those at $438.30 \mathrm{~nm}$ and $526.96 \mathrm{~nm}$ (both atomic lines) associated with iron. It is interesting to note that this decreasing order in the macro-elements intensity ( $\mathrm{K}, \mathrm{Ca}, \mathrm{Mg}$ and $\mathrm{Fe}$ ) broadly matches the elemental concentration decreasing order as measured by ICP-MS
(Table 1). Concerning the micro-elements, chromium is associated with the wavelength $520.83 \mathrm{~nm}$ (atomic line), and rubidium at $780.01 \mathrm{~nm}$ (atomic line) these could be seen in most samples. For all samples, atomic emission line of hydrogen at $656.24 \mathrm{~nm}$, nitrogen at $742.41 \mathrm{~nm}$, $744.28 \mathrm{~nm}$ and $746.91 \mathrm{~nm}$, together with oxygen at $777.43 \mathrm{~nm}$ could be observed; it is worth noting that all experiments involving LIBS were conducted under normal atmospheric conditions (i.e. no purge gases) [24].

Each aquafeed spectrum presented had a unique pattern (Fig. 1 A.). Indeed, whatever the element observed the general fish feed powder I presented the highest intensities. For $\mathrm{Na}, \mathrm{Ca}, \mathrm{Mg}, \mathrm{Fe}$ and $\mathrm{Cr}$ the sample's decreasing order of intensities are similar i.e. carp grower, telapia nursery and pangus finisher while for $\mathrm{K}$ it is telapia nursery first then carp starter and finally pangus finisher. Ideally, the LIBS measurements would always match the chemical concentration ordering of the ICP-MS analysis. However, LIBS can be affected by factors including; self-absorption and matrix effects, leading to emission line intensities no longer proportional to the concentration of the element in the plasma. In order to summarise the structure of the data in a lower dimensional space a PCA was applied on the entire LIBS spectra (only baseline corrected) of 4 aquafeeds (carp starter, pangus finisher, telapia nursery and general fish feed powder I). The resulting PCA score plot of the first two principal components (PC) is depicted in Fig. 2. PC1 and PC2 accounted respectively for $16.6 \%$ and $4.6 \%$ of the total variance. The four previously defined types of aquafeeds, enclosed by their respective $95 \%$ confidences, can be distinguished principally by PC1. Pangus finisher samples are on left of the figure, while general fish feed powder I samples plot on the right side. Telapia nursery and carp starter samples lie between the two other groups (Fig. 2).

In agreement with Fig. 1 A., samples with similar spectral patterns show clusters with a slight overlap, such as carp starter and telapia nursery. On the other hand, samples with different spectral patterns between samples (Fig. 1 A.), and therefore elemental composition, show distinct clusters such as pangus finisher and general fish feed powder I, where in Fig. 2, a clear separation can be seen. This is consistent with the PCA loading plot data (Fig. i) in supplementary information.

\subsection{Quantitative set}

\subsubsection{LIBS spectral analysis}

For clarification, the median LIBS spectra obtained from three different samples: $100 \%$ binder, $40 \%$ general fish feed powder II $(60 \%$ binder) and $80 \%$ general fish feed powder II (20\% binder) are presented in Fig. 3. A clear increase in the intensity of $\mathrm{Cr}(520.83 \mathrm{~nm})$, Ca $(393.39 \mathrm{~nm}, 422.65 \mathrm{~nm}$ and $643.93 \mathrm{~nm}), \mathrm{Mg}(279.56 \mathrm{~nm}$ and $518.40 \mathrm{~nm}), \mathrm{K}(766.46 \mathrm{~nm}$ and $769.93 \mathrm{~nm}), \mathrm{Fe}(526.96 \mathrm{~nm})$ and $\mathrm{Rb}$ (780.01 nm) emission lines for samples with an increasing amount of feed content can be observed. Indeed, whatever the element, the maximum intensities were observed for the $80 \%$ feed sample (Fig. 1 B.c) while the lowest intensities or no peaks are observed for the $100 \%$ binder (Fig. 1 B.a), i.e. $0 \%$ feed. These results are promising for the use 

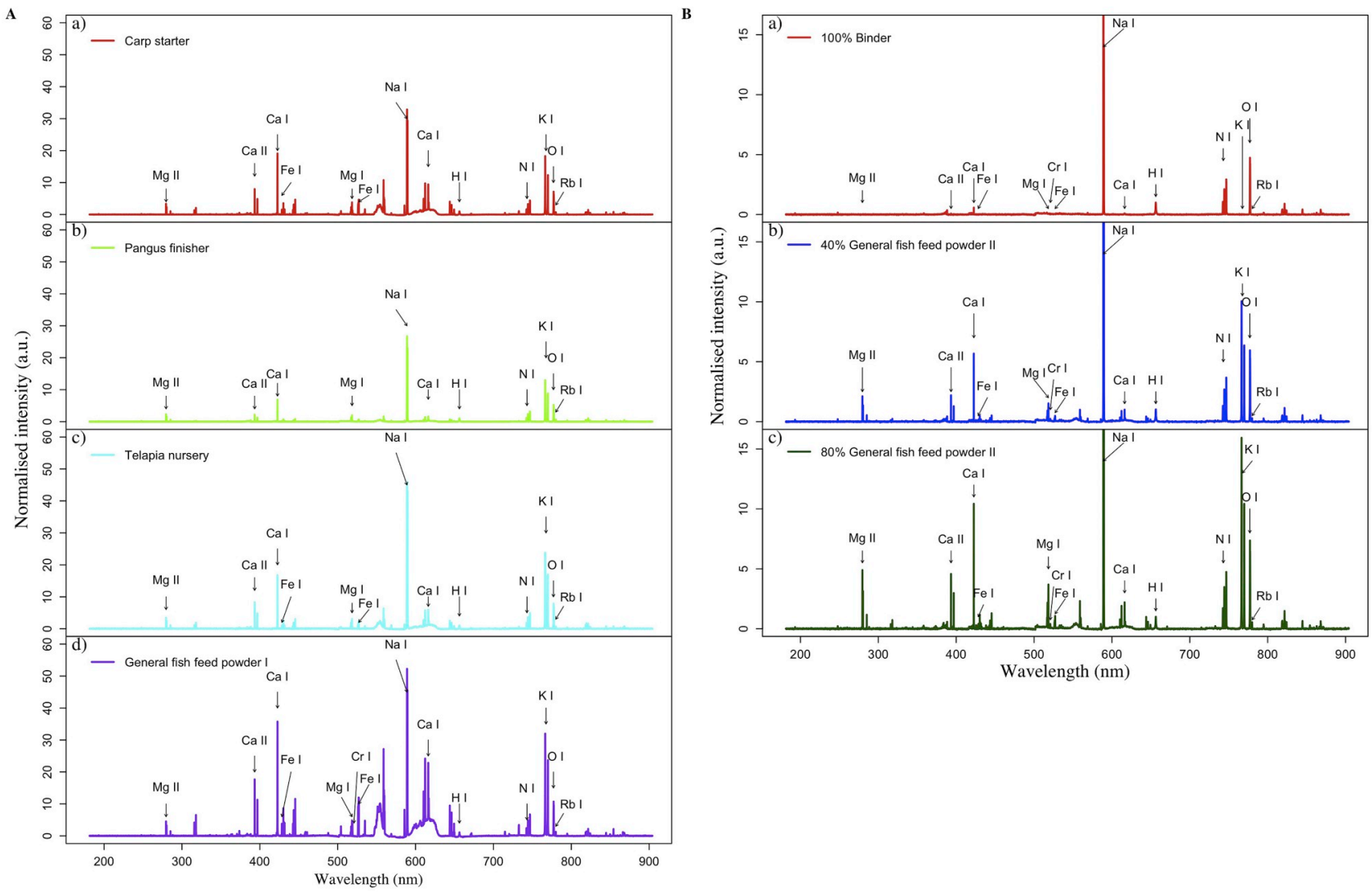

Fig. 1. Median LIBS spectra of A. 4 different aquafeeds: a) Carp starter, b) Pangus finisher, c) Telapia nursery and d) General fish feed powder I. B. 3 mixtures with different proportion of binder and aquafeed: a) 100\% Binder, b) $40 \%$ General fish feed powder II, c) $80 \%$ General fish feed powder II. Spectra are vertically offset for clarity. The Roman numeral "I" refers to the neutral atom and "II" to the singly-ionized state of the chemical element.

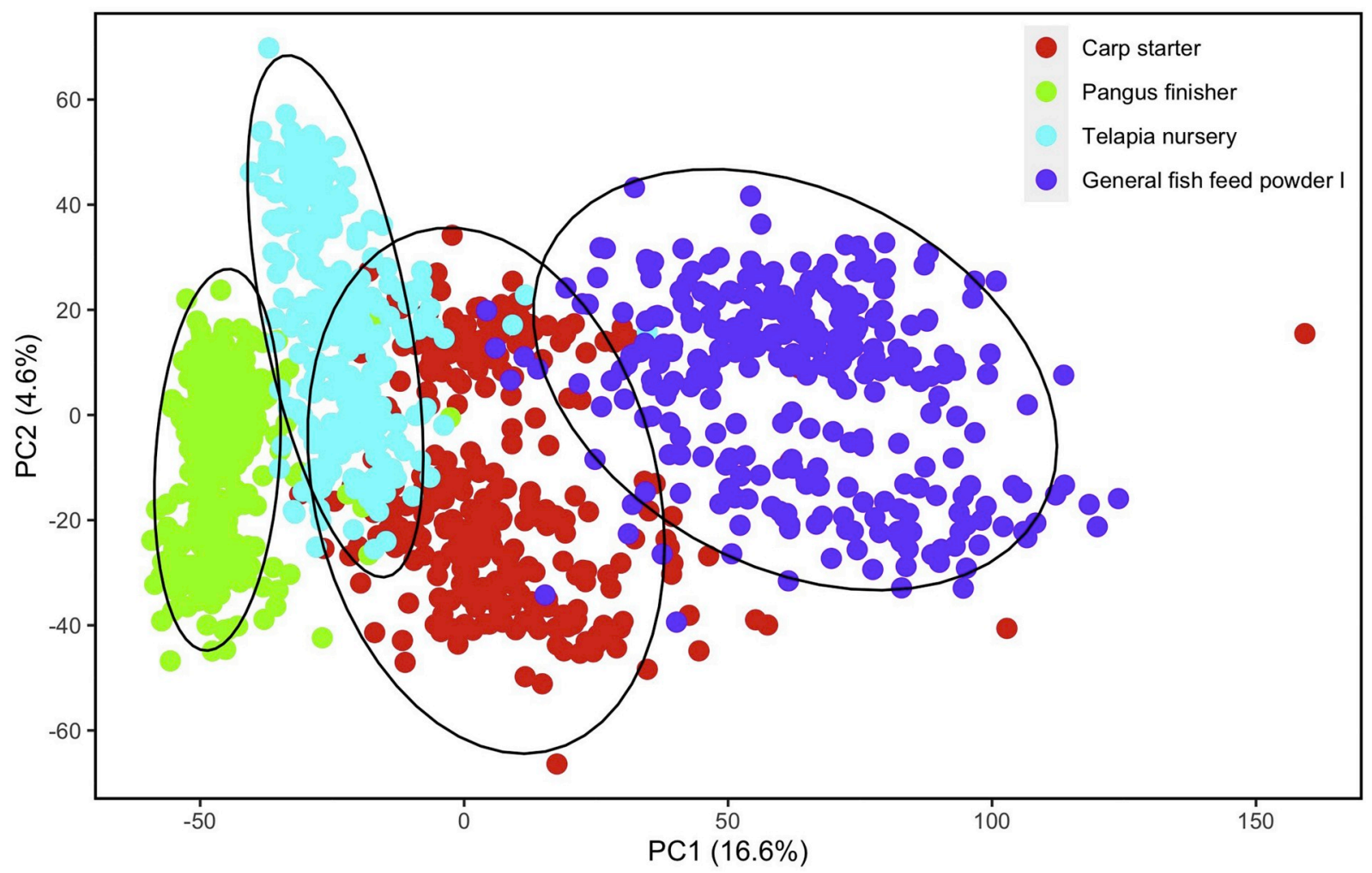

Fig. 2. Score plot of PC1 vs PC2 of a principal component analysis on LIBS spectra of 4 different aquafeeds (carp starter, pangus finisher, telapia nursery and general fish feed powder I) with their $95 \%$ confidence ellipses. 

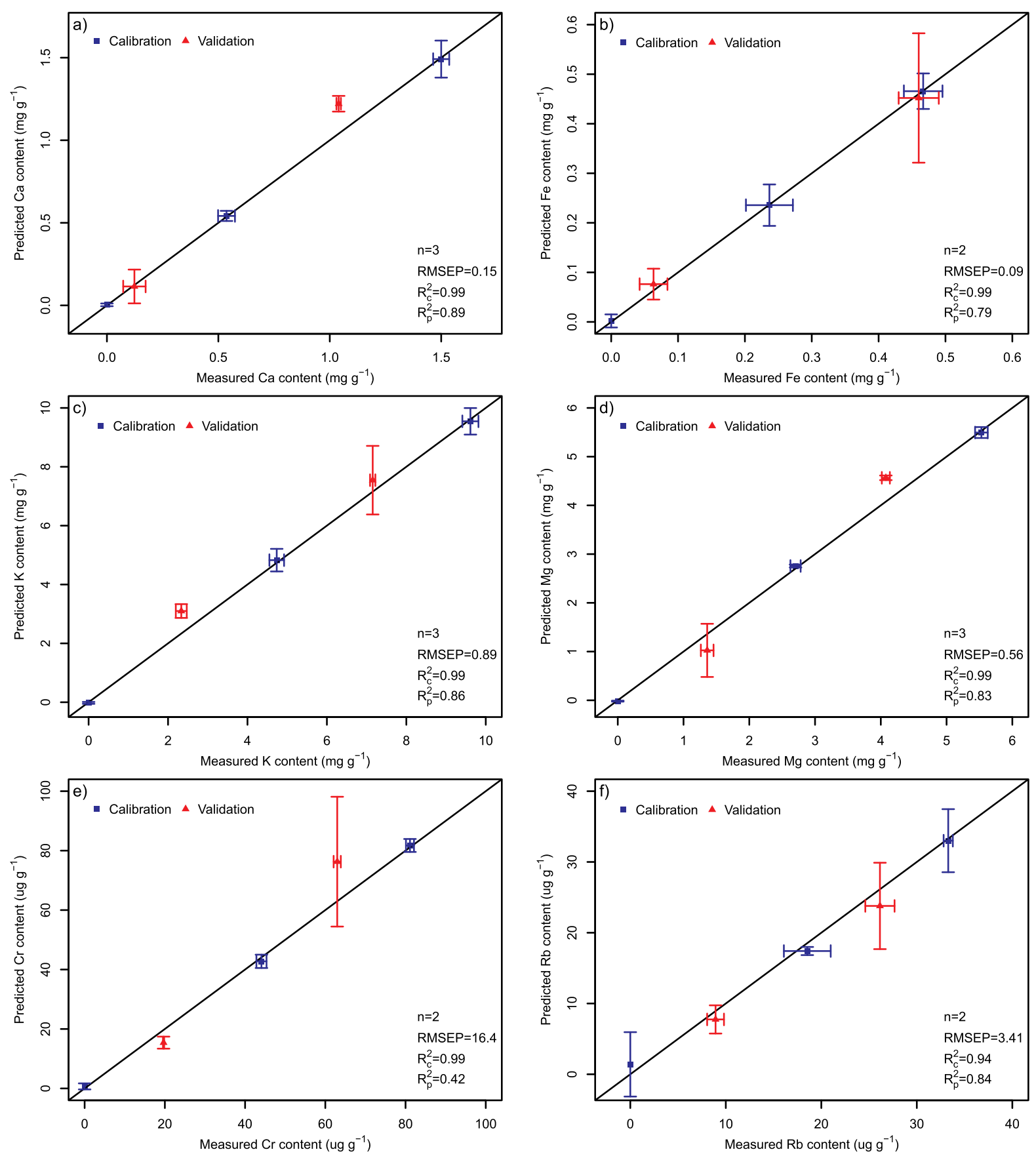

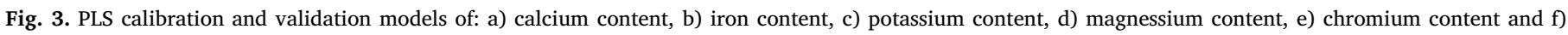
rubidium content in general fish feed powder II.

of LIBS in quantitative analysis of aquafeed.

\subsubsection{Calibration and validation models}

Calibration models were constructed using PLS regression performed on a calibration data set $(100 \%$ binder, $40 \%$ feed and $80 \%$ feed). The concentrations determined by ICP-MS were utilized as observed variables for PLSR, thus relating elements ( $\mathrm{Ca}, \mathrm{Cr}, \mathrm{Fe}, \mathrm{K}, \mathrm{Mg}$ and $\mathrm{Rb})$ to pre-processed LIBS spectra data. As mention above, the full preprocessed LIBS spectra data were not used but wavelength range specific to each element of interest such as $460.46 \mathrm{~nm}-460.92 \mathrm{~nm}$ and $519.55 \mathrm{~nm}-522.11 \mathrm{~nm}$ for Cr. A key parameter in the construction of a robust, neither over- nor under-fitted model, is the selection of the optimum numbers of PLS factors. Indeed, too many factors may lead to an unstable model which over-fit the data implying a random noise instead of the link between observations and predictions. Conversely, too few factors may lead to an under-fitted model integrating inadequate information of data [25]. Cross-validated (CV) prediction using the leave-one-out method was applied in this study to increase the model accuracy and determine the optimum number of latent variables based at the same time on a low root mean square error of $\mathrm{CV}$ (RMSECV) and a high $\mathrm{R}_{\mathrm{cv}}^{2}$. Table 2 summarized the performance of the calibration model: number of PLS factors, coefficients of determination and root mean square errors for calibration $\left(\mathrm{R}_{c}^{2}, \mathrm{RMSEC}\right)$, cross-validation $\left(\mathrm{R}_{\mathrm{cv}}^{2}\right.$, RMSECV) and prediction $\left(\mathrm{R}_{\mathrm{p}}^{2}\right.$, RMSEP) by an independent data set. The optimum number of PLS factors is 3 for $\mathrm{Ca}, \mathrm{K}$ and $\mathrm{Mg}$ while it is 2 for $\mathrm{Fe}, \mathrm{Cr}$ and $\mathrm{Rb}$ (Table 2). Moreover, as displayed in 
Table 2

Calibration Cross-validation and prediction performance parameters of PLSR models using LIBS.

\begin{tabular}{|c|c|c|c|c|c|c|c|}
\hline \multirow[t]{2}{*}{ Element } & \multirow{2}{*}{$\begin{array}{l}\text { No. } \\
\text { PLS } \\
\text { factors }\end{array}$} & \multicolumn{2}{|c|}{ Calibration $(n=9)$} & \multicolumn{2}{|c|}{ Cross-validation } & \multicolumn{2}{|c|}{ Validation $(n=6)$} \\
\hline & & $\mathrm{R}_{\mathrm{c}}^{2}$ & RMSEC $^{\mathrm{a}}$ & $\mathrm{R}_{\mathrm{cv}}^{2}$ & RMSECV $^{\mathrm{a}}$ & $\mathrm{R}_{\mathrm{p}}^{2}$ & RMSEP $^{a}$ \\
\hline $\mathrm{Ca}$ & 3 & 0.99 & 0.06 & 0.90 & 0.19 & 0.89 & 0.15 \\
\hline $\mathrm{Fe}$ & 2 & 0.99 & 0.01 & 0.94 & 0.04 & 0.79 & 0.09 \\
\hline $\mathrm{K}$ & 3 & 0.99 & 0.30 & 0.94 & 0.94 & 0.86 & 0.89 \\
\hline $\mathrm{Mg}$ & 3 & 0.99 & 0.13 & 0.97 & 0.36 & 0.83 & 0.56 \\
\hline $\mathrm{Cr}$ & 2 & 0.99 & 1.34 & 0.99 & 2.87 & 0.42 & 16.4 \\
\hline $\mathrm{Rb}$ & 2 & 0.94 & 3.36 & 0.71 & 7.34 & 0.84 & 3.41 \\
\hline
\end{tabular}

a Expressed in milligrams per gram for macro-elements ( $\mathrm{Ca}, \mathrm{Fe}, \mathrm{K}$ and $\mathrm{Mg}$ ) and micrograms per gram for micro-elements ( $\mathrm{Cr}$ and $\mathrm{Rb})$.

Fig. 3, which shows the scatter plot of the measured and predicted content of element of interest, a good linearity of the model whatever the element could be showed. Table 2 and Fig. 3 show a $R_{c}^{2}$ for most of the elements equal to 0.99 (except of $\mathrm{Rb} 0.94$ ) and $\mathrm{R}_{\mathrm{cv}}^{2}$ higher than 0.90 (except of $\mathrm{Rb}$ 0.71). The slightly decreased values between the calibration and cross-validation root square $\left(\mathrm{R}_{\mathrm{c}}^{2}\right.$ and $\mathrm{R}_{\mathrm{cv}}^{2}$ respectively) and the slight increase between RMSEC and RMSECV point to models that are not over fitted.

The robustness of calibration models was assessed by applying the 6 models on the validation data set. Fig. 3 shows a good prediction for all elements with both RMSEP and RMSECV values similar, indicating a robust model.

Lower correlation for $\mathrm{Cr}\left(\mathrm{R}_{\mathrm{p}}^{2}\right)$ and higher RMSEP compared to other elements presented in this study is probably due to the low $\mathrm{Cr}$ content in fish feed and the fact that natural material, even finely crushed remains heterogeneous. More replicates and/or more samples could improve prediction model.

According to these results, it can be concluded that the prediction models have a good performance in predicting $\mathrm{Ca}, \mathrm{Fe}, \mathrm{K}, \mathrm{Mg}, \mathrm{Cr}$ and $\mathrm{Rb}$ in aquafeeds.

\subsubsection{Chemical maps}

In order to study the $\mathrm{Cr}$ distribution within a sample, an intensity map displaying the 100 locations analysed per sample at $520.83 \mathrm{~nm}$ is presented in Fig. 4. Fig. 4 (a)-(e) show the intensity distribution of $\mathrm{Cr}$ at $520.83 \mathrm{~nm}$ of the calibration set from $100 \%$ binder content (Fig. $4 \mathrm{a}$ ) to $80 \%$ general fish feed powder II content (Fig. 4e). An obvious distinction between different mixtures of feed percentages is viewed based on their $\mathrm{Cr}$ line intensity, indicated by the colour scale from dark blue for low intensities to dark red/brown for high intensities. Indeed in the binder, where there is no chromium the pellet is represented as a completely dark blue matrix (Fig. 4a), whereas the $80 \%$ fish feed is dark red/brown (Fig. 4e) and in between samples a colour scale explaining proportionate concentrations. These spatial distribution maps demonstrate that the intensity of $\mathrm{Cr}$ is directly proportional to the feed content.

To further explain the spatial distribution capabilities of LIBS, two supplementary pellets containing two different mixtures of the feed content were analysed. Fig. 4 (f) and Fig. 4 (g) represent the Cr intensity distribution in 2 pellets containing on one side with $100 \%$ binder and their corresponding half a 80:20 ratio $\left(\mathrm{w} \mathrm{w}^{-1}\right)$ and 40:60 ratio $\left(\mathrm{w} \mathrm{w}^{-1}\right)$ of binder to general fish feed powder II. For both pellets, a colour scale could be observed from the $100 \%$ binder side, which is a dark blue, and the mixture of binder and aquafeed, which is light blue for 80:20 mixture and blue-green with orange spot in the 40:60 mixture. These two figures (Fig. $4 \mathrm{f}$ and $\mathrm{g}$ ) also demonstrate that LIBS can spatially distinguish chromium (Cr) intensity within the pellet.

\section{Conclusion}

The present work demonstrates the feasibility of LIBS combined with chemometric techniques as a rapid analytical technique for qualitative and quantitative analysis of calcium, chromium, iron, magnesium, potassium and rubidium content in different types of fish feed samples. The main advantages of LIBS technique compared to reference methods for element content determination are its rapidness, userfriendliness and minimal sample preparation. PLS regression for each
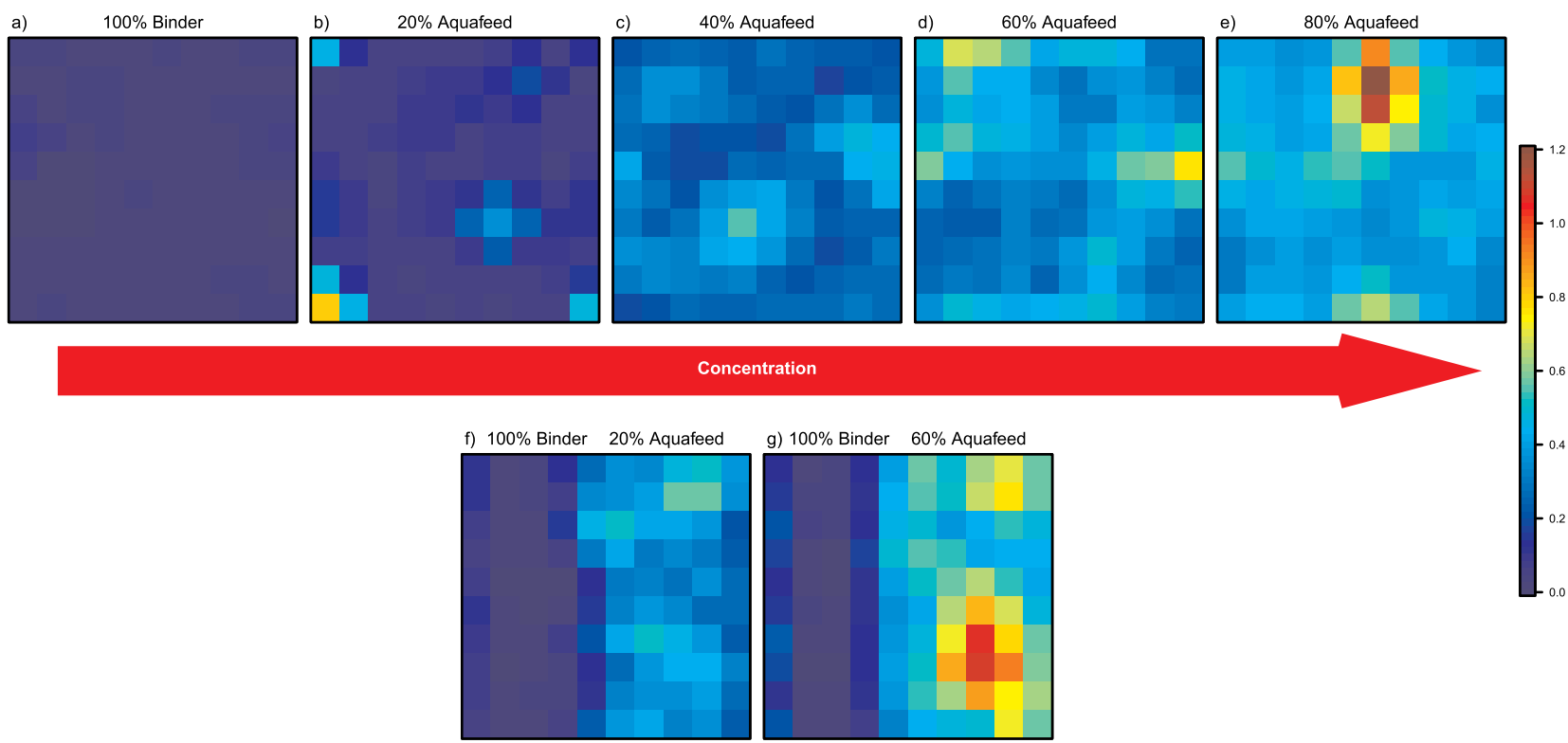

oncentration

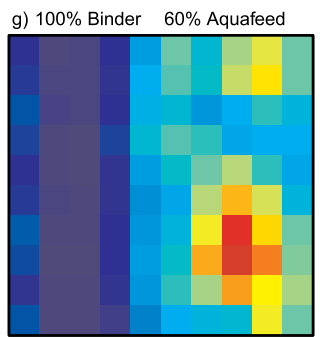

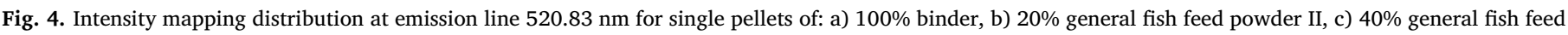

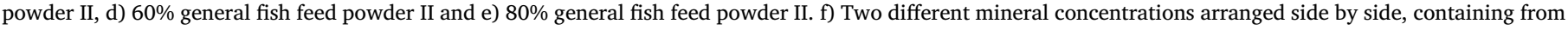

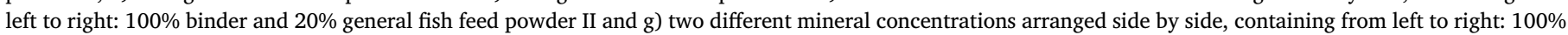

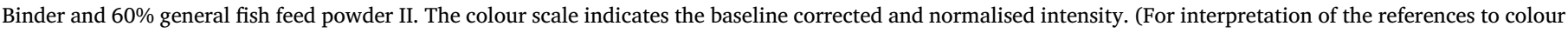
in this figure legend, the reader is referred to the Web version of this article.) 
element was performed to build a model allowing their quantification in aquafeeds. The results illustrate that LIBS offers the potential to detect and quantify minerals in fish feed, offering potential for real-time monitoring of elemental composition. Moreover, the chemical cartography conducted in this study allows a better understanding of chromium distribution within samples. The findings illustrate the ability of LIBS to identify not only the chemical composition of feed samples but also the spatial elemental distribution.

The technology has the potential to offer in-field or process analysis of fish feed. However, further studies are required to identify other elements, strengthen the models and make LIBS a suitable technique for routine analysis in an industrial environment.

\section{Author agreement statement}

We the undersigned declare that this manuscript is original, has not been published before and is not currently being considered for publication elsewhere. We confirm that the manuscript has been read and approved by all named authors and that there are no other persons who satisfied the criteria for authorship but are not listed. We further confirm that the order of authors listed in the manuscript has been approved by all of us. We understand that the Corresponding Author is the sole contact for the Editorial process. He is responsible for communicating with the other authors about progress, submissions of revisions and final approval of proofs.

\section{Declaration of competing interest}

The authors declare that they have no known competing financial interests or personal relationships that could have appeared to influence the work reported in this paper.

\section{Acknowledgments}

This research did not receive any specific grant from funding agencies in the public, commercial, or not-for-profit sectors. The author would like to thanks the Environmental Sustainability and Health Institute (ESHI) for the support received during chemical analysis.

\section{Appendix A. Supplementary data}

Supplementary data to this article can be found online at https:// doi.org/10.1016/j.talanta.2020.121258.

\section{References}

[1] G.M.R. Islam, F.E. Khan, M.M. Hoque, Y.N. Jolly, Consumption of unsafe food in the adjacent area of Hazaribag tannery campus and Buriganga River embankments of Bangladesh: heavy metal contamination, Environ. Monit. Assess. 186 (2014) 7233-7244, https://doi.org/10.1007/s10661-014-3923-2.

[2] J. Jothi, N. Yeasmin, I. Anka, S. Hashem, Chromium and lead contamination in commercial poultry feeds of Bangladesh, Int. J. Agric. Res. Innovat. Technol. 6 (2017) 57-60, https://doi.org/10.3329/ijarit.v6i2.31705.

[3] M. Islam, M. Shoeb, R. Islam, N. Nahar, Heavy metals contamination in marine fish samples of Bangladesh, J. Food Nutr. Sci. 1 (2018) 4-11.

[4] A.K. Psoma, I.N. Pasias, N.I. Rousis, K.A. Barkonikos, N.S. Thomaidis, Development , validation and accreditation of a method for the determination of $\mathrm{Pb}, \mathrm{Cd}, \mathrm{Cu}$ and As in seafood and fish feed samples, Food Chem. 151 (2014) 72-78, https://doi. org /10.1016/j.foodchem.2013.11.045.

[5] W. Sabbir, M.Z. Rahman, T. Halder, M.N. Khan, S. Ray, Assessment of heavy metal contamination in fish feed available in three districts of South Western region of Bangladesh, Int. J. Fish. Aquat. Stud. 6 (2018) 100-104.

[6] S.O. Souza, T.R.S. Pereira, D.V.L. Ávila, L.B. Paixão, S.A.R. Soares, A.F.S. Queiroz,
A.G.G. Pessoa, M. das, G.A. Korn, T.A. Maranhão, R.G.O. Araujo, Optimization of sample preparation procedures for evaluation of the mineral composition of fish feeds using ICP-based methods, Food Chem. 273 (2019) 106-114, https://doi.org/ 10.1016/j.foodchem.2018.01.178.

[7] M.S. Kawamoto, G.B. de Souza, A.R. de Araujo Nogueira, Preparation and evaluation of a new reference material for macro- and micronutrients in fish feed, Microchem. J. 149 (2019) 104027, https://doi.org/10.1016/j.microc.2019. 104027.

[8] M. Markiewicz-Keszycka, X. Cama-Moncunill, M.P. Casado-Gavalda, Y. Dixit, R. Cama-Moncunill, P.J. Cullen, C. Sullivan, Laser-induced breakdown spectroscopy (LIBS) for food analysis: a review, Trends Food Sci. Technol. 65 (2017) 80-93, https://doi.org/10.1016/j.tifs.2017.05.005.

[9] G.S. Senesi, J. Cabral, C.R. Menegatti, B. Marangoni, G. Nicolodelli, Recent advances and future trends in LIBS applications to agricultural materials and their food derivatives: an overview of developments in the last decade (2010-2019). Part II. Crop plants and their food derivatives, TrAC Trends Anal. Chem. (Reference Ed.) 118 (2019) 453-469, https://doi.org/10.1016/j.trac.2019.05.052.

[10] M.A. Gondal, Y.B. Habibullah, U. Baig, L.E. Oloore, Direct spectral analysis of tea samples using $266 \mathrm{~nm}$ UV pulsed laser-induced breakdown spectroscopy and cross validation of LIBS results with ICP-MS, Talanta 152 (2016) 341-352, https://doi. org/10.1016/j.talanta.2016.02.030.

[11] N. Baskali-Bouregaa, M.L. Milliand, S. Mauffrey, E. Chabert, M. Forrestier, N. Gilon, Tea geographical origin explained by LIBS elemental profile combined to isotopic information, Talanta 211 (2020) 120674, https://doi.org/10.1016/j.talanta.2019. 120674.

[12] Y. Dixit, M.P. Casado-Gavalda, R. Cama-Moncunill, M. Markiewicz-Keszycka, X. Cama-Moncunill, P.J. Cullen, C. Sullivan, Quantification of rubidium as a trace element in beef using laser induced breakdown spectroscopy, Meat Sci. 130 (2017) 47-49, https://doi.org/10.1016/j.meatsci.2017.03.013.

[13] M. Markiewicz-Keszycka, M.P. Casado-Gavalda, X. Cama-Moncunill, R. CamaMoncunill, Y. Dixit, P.J. Cullen, C. Sullivan, Laser-induced breakdown spectroscopy (LIBS) for rapid analysis of ash, potassium and magnesium in gluten free flours, Food Chem. 244 (2018) 324-330, https://doi.org/10.1016/j.foodchem.2017.10. 063.

[14] P. Yang, R. Zhou, W. Zhang, R. Yi, S. Tang, L. Guo, Z. Hao, X. Li, Y. Lu, X. Zeng, High-sensitivity determination of cadmium and lead in rice using laser-induced breakdown spectroscopy, Food Chem. 272 (2019) 323-328, https://doi.org/10. 1016/j.foodchem.2018.07.214

[15] J. Peng, Y. He, Z. Zhao, J. Jiang, F. Zhou, F. Liu, T. Shen, Fast visualization of distribution of chromium in rice leaves by re-heating dual-pulse laser-induced breakdown spectroscopy and chemometric methods, Environ. Pollut. 252 (2019) 1125-1132, https://doi.org/10.1016/j.envpol.2019.06.027.

[16] L.C. Peruchi, L.C. Nunes, G.G.A. De Carvalho, M.B.B. Guerra, E. De Almeida, I.A. Rufini, D. Santos, F.J. Krug, Determination of inorganic nutrients in wheat flour by laser-induced breakdown spectroscopy and energy dispersive X-ray fluorescence spectrometry, Spectrochim. Acta Part B At. Spectrosc. 100 (2014) 129-136, https:// doi.org/10.1016/j.sab.2014.08.025.

[17] A.N.S. Dantas, W.O. Matos, S.T. Gouveia, G.S. Lopes, The combination of infrared and microwave radiation to quantify trace elements in organic samples by ICP OES, Talanta 107 (2013) 292-296, https://doi.org/10.1016/j.talanta.2013.01.047.

[18] W. da Luz Lopes, R.E. Santelli, E.P. Oliveira, M. de F.B. de Carvalho, M.A. Bezerra, Application of multivariate techniques in the optimization of a procedure for the determination of bioavailable concentrations of Se and As in estuarine sediments by ICP OES using a concomitant metals analyzer as a hydride generator, Talanta 79 (2009) 1276-1282, https://doi.org/10.1016/j.talanta.2009.05.039.

[19] R.C. Team, The R Project for Statistical Computing, (2019) https://www.r-project. org/.

[20] B.-H. Mevik, R. Wehrens, K.H. Liland, Partial Least Squares and Principal Component Regression, (2019) https://cran.r-project.org/web/packages/pls/ index.html.

[21] N. Labbe, I.M. Swamidoss, N. André, M.Z. Martin, T.M. Young, T.G. Rials, Extraction of information from laser-induced breakdown spectroscopy spectral data by multivariate analysis, Appl. Optic. 47 (2008) G158-G165, https://doi.org/10 1364/AO.47.00G158.

[22] H. Abdi, Partial least squares regression and projection on latent structure regression (PLS Regression), Wiley Interdiscip. Rev. Comput. Stat. 2 (2010) 97-106, https://doi.org/10.1002/wics.51.

[23] A. Kramida, Y. Ralchenko, J. Reader, Nist Asd team, Atomic Spectra Database: NIST Standard Reference Database 78, (2019), https://doi.org/10.18434/T4W30F Version 5.7.1.

[24] D.A. Cremers, L.J. Radziemski, Handbook of Laser-Induced Breakdown Spectroscopy, second ed., (2013), https://doi.org/10.1002/9781118567371 Handb. Laser-Induced Break. Spectrosc. Second Ed.

[25] B.C. Deng, Y.H. Yun, Y.Z. Liang, D.S. Cao, Q.S. Xu, L.Z. Yi, X. Huang, A new strategy to prevent over-fitting in partial least squares models based on model population analysis, Anal. Chim. Acta 880 (2015) 32-41, https://doi.org/10.1016/j.aca.2015. 04.045. 